\title{
Effect of renal impairment on the pharmacokinetics of levomilnacipran following a single oral dose of levomilnacipran extended-release capsule in humans
}

\author{
Laishun Chen \\ William M Greenberg \\ Elimor Brand-Schieber \\ Julie Wangsa \\ Antonia Periclou \\ Parviz Ghahramani
}

Forest Research Institute, a subsidiary of Actavis Inc., Jersey City, NJ, USA

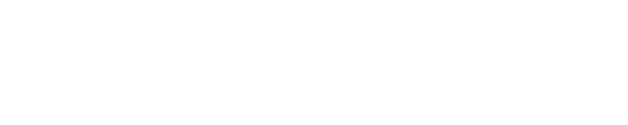

Purpose: Levomilnacipran extended-release (ER) is indicated for treatment of major depressive disorder in adults. We evaluated the pharmacokinetic and safety profile of levomilnacipran ER in individuals with impaired renal function.

Methods: A total of 32 individuals participated in four groups (eight in each group) with normal, mild, moderately, or severely impaired renal function. Each participant received one dose of levomilnacipran ER $40 \mathrm{mg}$. Blood and urine were assayed using liquid chromatography/tandem mass spectrometry. Results between normal and renally impaired groups were compared using analysis of variance. Safety measures included adverse events, laboratory evaluations, vital signs, suicidality, and electrocardiograms.

Results: Following administration of levomilnacipran, mean (standard deviation) maximum plasma concentration in participants with normal renal function, and mild, moderate, or severe renal impairment was 83.9 (21.0), 81.8 (23.4), 98.7 (18.1), and $122.1(35.1)(\mathrm{ng} / \mathrm{mL})$, respectively; area under the curve from time zero to infinity was 2,101.0 (516.9), 2,587.8 (649.9), 4,016.4 (995.4), and 5,900.8 (1,799.3) (h.ng/mL), respectively; terminal elimination half-life was 13.5 (2.8), 17.3 (3.5), 19.1 (4.6), and 27.7 (7.4) (hours), respectively; and renal clearance was $175.9 \mathrm{~mL} / \mathrm{min}, 114.7 \mathrm{~mL} / \mathrm{min}, 69.9 \mathrm{~mL} / \mathrm{min}$, and $28.6 \mathrm{~mL} / \mathrm{min}$, respectively. Levomilnacipran ER was generally well tolerated with no safety issues of concern identified.

Conclusion: Renal impairment was associated with increased plasma levels of levomilnacipran and prolonged half-life. No dose adjustment is required for individuals with mild renal impairment; the recommended maximum daily maintenance dose of levomilnacipran ER should not exceed $80 \mathrm{mg}$ for individuals with moderate renal impairment and $40 \mathrm{mg}$ for individuals with severe renal impairment.

Keywords: antidepressant, F2695, SNRI, pharmacokinetics, renal function, major depressive disorder

\section{Introduction}

Levomilnacipran (1S, 2R-milnacipran) is a serotonin and norepinephrine reuptake inhibitor (SNRI) with a greater potency for norepinephrine reuptake inhibition than for serotonin reuptake inhibition in vitro. An extended-release (ER) formulation of levomilnacipran was developed to allow for once-daily dosing. Levomilnacipran ER capsules $\left(\right.$ FETZIMA $\left.^{\circledR}\right)$ received US Food and Drug Administration (FDA) approval in July 2013 for the treatment of major depressive disorder in adults, with a recommended dose of 40-120 mg once daily. ${ }^{1}$
Correspondence: Laishun Chen Forest Research Institute, Harborside Financial Center, Plaza 5 24th FI (Room 68), Jersey City, NJ 073 II, USA $\mathrm{Tel}+\mathrm{I} 20$ |4278246

Fax + I 2014278498

Email laishun.chen@actavis.com 
The pharmacokinetics of levomilnacipran are dose proportional (single-dose range of 25-120 mg and multiple-dose range of 25-300 mg/day), and steady-state pharmacokinetics are predictable from single-dose data. ${ }^{1}$ Levomilnacipran is well absorbed following administration of the ER capsule, with a bioavailability of $92 \%$ relative to oral solution; food has no effect on the bioavailability. ${ }^{1}$ Levomilnacipran has a mean apparent terminal elimination half-life $\left(T_{1 / 2}\right)$ of approximately 12 hours. On the basis of results from a human mass balance study using ${ }^{14} \mathrm{C}$-labeled levomilnacipran, $58 \%$ of the radioactivity of an oral dose was recovered in urine as unchanged levomilnacipran. ${ }^{1}$ The major metabolite of levomilnacipran recovered in urine is $N$-desethyl levomilnacipran, accounting for approximately $18 \%$ of the total administered radioactivity. Other metabolites excreted in the urine are levomilnacipran glucuronide (4\%), desethyl levomilnacipran glucuronide (3\%), $p$-hydroxy levomilnacipran glucuronide (1\%), and $p$-hydroxy levomilnacipran (1\%). None of the metabolites identified are pharmacologically active. Levomilnacipran is widely distributed with an apparent volume of distribution of 387-473 L; plasma protein binding is $22 \%$ over the concentration range of 10-1,000 ng/mL. ${ }^{1}$

As described above, urinary excretion was the predominant elimination pathway for levomilnacipran and its metabolites. Renal impairment can alter the pharmacokinetic profile of many drugs, particularly drugs with significant elimination via renal excretion. To investigate how renal impairment affects the pharmacokinetic behavior of levomilnacipran ER, a single-dose pharmacokinetic study was conducted in individuals with mild, moderate, or severe renal impairment, as well as in a cohort of sex-, age-, and weight-matched individuals with normal renal function.

\section{Materials and methods Participants and study design}

A total of 32 men and women, 32-76 years of age, individuals with renal impairment and normal renal function, participated in this single-dose, open-label, parallel-group study. The study was conducted at two centers in the United States. Both centers received approval from independent ethics committees, and the study was conducted in accordance with the International Conference on Harmonisation Guidances on General Considerations for Clinical Trials, Nonclinical Safety Studies for the Conduct of Human Clinical Trials for Pharmaceuticals, and Good Clinical Practice guidelines. Signed informed consent was obtained from each participant before any study-related procedures were performed.
On day 1, participants were allocated into four groups (eight participants in each group) on the basis of estimated creatinine clearance $\left(\mathrm{CL}_{\mathrm{cr}}\right)$ values using the CockcroftGault equation. ${ }^{2}$ The four groups were defined as normal renal function $\left(\mathrm{CL}_{\mathrm{cr}} \geq 80 \mathrm{~mL} / \mathrm{min}\right)$, mild renal impairment $\left(\mathrm{CL}_{\text {cr }} \geq 50 \mathrm{~mL} / \mathrm{min}\right.$ and $\left.<80 \mathrm{~mL} / \mathrm{min}\right)$, moderate renal impairment $\left(\mathrm{CL}_{\mathrm{cr}} \geq 30 \mathrm{~mL} / \mathrm{min}\right.$ and $\left.<50 \mathrm{~mL} / \mathrm{min}\right)$, and severe renal impairment $\left(\mathrm{CL}_{\mathrm{cr}} \geq 5 \mathrm{~mL} / \mathrm{min}\right.$ and $<30 \mathrm{~mL} / \mathrm{min}$ ). Participants with normal renal function were recruited after those with impaired renal function had been enrolled so that individuals with normal renal function could be matched as closely as possible by sex, age range, and weight range to those with impaired renal function. The study that began in August 2009 was completed in April 2010, and was designed in accordance with the FDA guidance for industry. ${ }^{3}$

Key exclusion criteria were moderate or heavy cigarette use ( $\geq 10$ cigarettes per day); sitting heart rate $>100$ or $<50$ beats per minute (bpm) at screening; pregnancy or not using adequate nonhormonal contraception (eg, nonhormonal intrauterine device, double-barrier methods); known hypersensitivity to SNRIs, selective serotonin reuptake inhibitors, or tricyclic antidepressants; clinically significant medical condition other than renal impairment; liver enzyme values greater than the upper limit of normal; clinically significant electrocardiogram (ECG) abnormalities; current or past (within last 5 years) alcohol/substance abuse or dependence; a history of narrow-angle glaucoma (controlled or uncontrolled); and a history of major depressive disorder or other psychiatric disorder except nongeneralized social phobia, as indicated by the Mini-International Neuropsychiatric Interview.

Concomitant medications were not permitted during the study, except for medications considered necessary to treat underlying disease states or medical conditions related to renal impairment. Participants requiring necessary treatment for renal impairment were instructed to take medications $\geq 2$ hours before study drug was administered. Participants could also be excluded if a medication taken $\geq 14$ days before the start of the study could potentially interfere with study outcomes, as judged by the investigator or study sponsor.

\section{Levomilnacipran dosing and pharmacokinetic sample collection}

All participants received a single $40 \mathrm{mg}$ oral dose of levomilnacipran ER with $240 \mathrm{~mL}$ of water on day 1 under fasting conditions. Participants were required to drink $120 \mathrm{~mL}$ of water every hour until 4 hours after dose administration to facilitate urine production. 
Blood and urine samples were collected over a 5-day period. Blood samples were collected at 0 hours (just before the dose was administered), and at 1 hour, 2 hours, 3 hours, 4 hours, 5 hours, 6 hours, 8 hours, 10 hours, 12 hours, 24 hours, 36 hours, 48 hours, 72 hours, and 96 hours after the dose was administered. A total of approximately $110 \mathrm{~mL}$ of blood was collected from each participant; $90 \mathrm{~mL}$ was used for analyses of levomilnacipran and $\mathrm{N}$-desethyl levomilnacipran concentrations in plasma ( 15 samples, $6 \mathrm{~mL}$ each), and $20 \mathrm{~mL}$ was used for clinical laboratory analyses (before and after dosing, $10 \mathrm{~mL}$ each). Urine specimens were collected at -2 hours to 0 hours (just before the dose was administered), and at $0-4$ hours, $4-8$ hours, $8-12$ hours, $12-16$ hours, $16-32$ hours, $32-48$ hours, $48-72$ hours, and 72-96 hours after the dose was administered.

\section{Bioanalytical methods}

Plasma and urine samples were assayed to determine levomilnacipran and $N$-desethyl levomilnacipran concentrations using liquid chromatography/tandem mass spectrometry methods that had been validated to demonstrate their accuracy, precision, linearity, and reproducibility. ${ }^{4}$ For both analytes, the plasma assay method was linear over the concentration range of $1-200 \mathrm{ng} / \mathrm{mL}$ and had a lower limit of quantification of $1 \mathrm{ng} / \mathrm{mL}$ in $100 \mu \mathrm{L}$ of human plasma with $\mathrm{K}_{2}$ EDTA as the anticoagulant. The urinalysis method was linear for both analytes over the concentration range of $100-5,000 \mathrm{ng} / \mathrm{mL}$ and had a lower limit of quantification of $100 \mathrm{ng} / \mathrm{mL}$ in $50 \mu \mathrm{L}$ of human urine.

\section{Safety assessments}

Safety variables included adverse events (AEs), clinical laboratory values, vital signs (blood pressure and heart rate), ECG measurements, and suicidality (using the Columbia Suicide Severity Rating Scale). Treatment-emergent AEs (TEAEs) were defined as AEs that were not present at baseline or that were present at baseline but increased in severity during the treatment period, regardless of relationship to study drug.

\section{Statistical analyses}

\section{Pharmacokinetic analysis}

Pharmacokinetic parameters were calculated using noncompartmental analyses employing Phoenix WinNonlin software (version 6.1). Plasma and urine concentrations below the limit of quantification were treated as zero. Nominal sampling times were used to calculate pharmacokinetic parameters except when the nominal and actual sampling times were more than 5 minutes apart; in such cases, the actual sampling time was used. Pharmacokinetic parameters for levomilnacipran included the maximum plasma drug concentration $\left(C_{\max }\right)$, area under the plasma concentration versus time curve from time zero to time $t\left(\mathrm{AUC}_{0-t}\right)$ and from time zero to infinity $\left(\mathrm{AUC}_{0-\infty}\right)$, time of maximum plasma drug concentration $\left(T_{\max }\right), T_{1 / 2}$, renal clearance $\left(\mathrm{CL}_{\mathrm{r}}\right)$, apparent total clearance from plasma after extravascular administration $(\mathrm{CL} / \mathrm{F})$, apparent volume of distribution at steady state after extravascular administration $\left(V_{\mathrm{ss}} / \mathrm{F}\right)$ and during the terminal phase after extravascular administration $\left(V_{z} / \mathrm{F}\right)$, cumulative amount of compound excreted unchanged into urine from time zero to time $t\left(\mathrm{Ae}_{0-t}\right)$, and percentage of compound excreted unchanged in urine relative to administered dose (fraction of dose). For the inactive metabolite, $\mathrm{N}$-desethyl levomilnacipran, the following pharmacokinetic parameters were determined: $C_{\max }, T_{\max }, \mathrm{AUC}_{0-t}, \mathrm{AUC}_{0-\infty}$ $T_{1 / 2}$, and $\mathrm{Ae}_{0-t}$.

Descriptive statistics were used to summarize all pharmacokinetic and safety data. Log-transformed $C_{\max }, \mathrm{AUC}_{0-t}$, and $\mathrm{AUC}_{0-\infty}$ for levomilnacipran and $\mathrm{N}$-desethyl levomilnacipran, if applicable, were compared between each of the impaired renal function groups and the normal renal function group using analysis of variance with group as a fixed effect in Phoenix WinNonlin software. Point estimates and $90 \%$ confidence intervals for differences between normal and impaired renal function groups on the log scale were exponentiated to obtain estimates for ratios of geometric means of $C_{\max }$, $\mathrm{AUC}_{0-t}$, and $\mathrm{AUC}_{0-\infty}$ on the original scale.

For levomilnacipran, the relationship between $\mathrm{CL} / \mathrm{F}$ versus $\mathrm{CL}_{\mathrm{cr}}$ and between $\mathrm{CL}_{\mathrm{r}}$ versus $\mathrm{CL}_{\mathrm{cr}}$ was evaluated by a linear regression model $Y=a+b \cdot X$ using SigmaPlot software (version 12.0). Dosing recommendations were proposed on the basis of the relationship between $\mathrm{CL} / \mathrm{F}$ and $\mathrm{CL}_{\mathrm{cr}}$ established in this study, overall safety profile of levomilnacipran, and available dosing strengths of the product $(20 \mathrm{mg}, 40 \mathrm{mg}, 80 \mathrm{mg}$, and $120 \mathrm{mg}$ ). For the purpose of dosing recommendations, classification into a renal function group was based on $\mathrm{CL}_{\mathrm{cr}}$ values as provided in the recent draft FDA guidance $(2010)^{5}$ that was released after initiation of this study: control $\left(\mathrm{CL}_{\mathrm{cr}} \geq 90 \mathrm{~mL} / \mathrm{min}\right)$, mild renal impairment $\left(\mathrm{CL}_{\mathrm{cr}} 60-89 \mathrm{~mL} / \mathrm{min}\right)$, moderate renal impairment $\left(\mathrm{CL}_{\mathrm{cr}} 30-59 \mathrm{~mL} / \mathrm{min}\right)$, and severe renal impairment $\left(\mathrm{CL}_{\mathrm{cr}}\right.$ $15-29 \mathrm{~mL} / \mathrm{min})$. Based on the regression line between $\mathrm{CL} / \mathrm{F}$ and $\mathrm{CL}_{\mathrm{cr}}, \mathrm{CL} / \mathrm{F}$ values were determined for the midpoint $\mathrm{CL}_{\text {cr }}$ value of each renal impairment group, ie, $74.5 \mathrm{~mL} /$ min, $44.5 \mathrm{~mL} / \mathrm{min}$, and $22 \mathrm{~mL} / \mathrm{min}$ for mild, moderate, and severe renal impairment, respectively. For the purpose of comparing the $\mathrm{CL} / \mathrm{F}$ value of each renally impaired group to the normal group using the linear regression model, the 
Table I Demographic characteristics by renal function

\begin{tabular}{|c|c|c|c|c|}
\hline & $\begin{array}{l}\text { Normal } \\
\text { function }(n=8)\end{array}$ & $\begin{array}{l}\text { Mild } \\
\text { impairment }(n=8)\end{array}$ & $\begin{array}{l}\text { Moderate } \\
\text { impairment }(n=8)\end{array}$ & $\begin{array}{l}\text { Severe } \\
\text { impairment }(n=8)\end{array}$ \\
\hline Age, years & 61.4 & 65.4 & 66.4 & 62.5 \\
\hline Women, n (\%) & $5(62.5)$ & $5(62.5)$ & $3(37.5)$ & $6(75.0)$ \\
\hline Weight, kg & 74.9 & 69.1 & 76.5 & 74.2 \\
\hline Body mass index, $\mathrm{kg} / \mathrm{m}^{2}$ & 27.7 & 24.7 & 26.2 & 27.6 \\
\hline $\mathrm{CL}_{\mathrm{cr}}, \mathrm{mL} / \mathrm{min}$ & 103.2 & 67.7 & 38.6 & 18.0 \\
\hline
\end{tabular}

Note: Data are mean values unless otherwise noted.

Abbreviation: $\mathrm{CL}_{\mathrm{cr}}$, creatinine clearance.

range of $\mathrm{CL}_{\mathrm{cr}}$ for the normal renal group was assumed to be $90-120 \mathrm{~mL} / \mathrm{min}$ with a midpoint of $105 \mathrm{~mL} / \mathrm{min}$. Based on the change in the predicted $\mathrm{CL} / \mathrm{F}$ value at the midpoint $\mathrm{CL}_{\mathrm{cr}}$ for each renally impaired group relative to the $\mathrm{CL} / \mathrm{F}$ for the normal renal function group, an appropriate dose was determined for each renally impaired group, assuming a dose of $120 \mathrm{mg}$ in the normal group.

\section{Safety analysis}

The safety population included all study participants who received the single dose of study drug. Safety data were analyzed using SAS software (version 9.1.3). Incidences were determined using the total number of study participants in each group. For calculation of mean changes from baseline to end of study, baseline was defined as the last assessment before administration of the study drug (ie, screening value).

\section{Results}

\section{Disposition and demographics}

All 32 participants completed the study and were included in the pharmacokinetic and safety analyses. No notable demographic differences were found among the subgroups, except for a lower percentage of women in the group with moderate renal impairment $(37.5 \%$ versus $>60 \%$ for other groups) (Table 1).

\section{Pharmacokinetics}

With the exception of $C_{\max }$ for levomilnacipran in participants with mild renal impairment, the $C_{\max }, \mathrm{AUC}_{0-t}$, and $\mathrm{AUC}_{0-\infty}$ values for both levomilnacipran and $N$-desethyl levomilnacipran were higher in participants with renal impairment than in healthy subjects (Table 2; Figure 1). In individuals with mild, moderate, and severe renal

Table 2 Mean (SD) pharmacokinetic parameters following a single dose of $40 \mathrm{mg}$ levomilnacipran ER by renal function

\begin{tabular}{|c|c|c|c|c|}
\hline $\begin{array}{l}\text { Pharmacokinetic } \\
\text { parameters }\end{array}$ & $\begin{array}{l}\text { Normal } \\
\text { function }(n=8)\end{array}$ & $\begin{array}{l}\text { Mild } \\
\text { impairment }(n=8)\end{array}$ & $\begin{array}{l}\text { Moderate } \\
\text { impairment }(n=8)\end{array}$ & $\begin{array}{l}\text { Severe } \\
\text { impairment }(n=8)\end{array}$ \\
\hline \multicolumn{5}{|l|}{ Levomilnacipran } \\
\hline$C_{\max }, \mathrm{ng} / \mathrm{mL}$ & $83.9(21.0)$ & $81.8(23.4)$ & $98.7(18.1)$ & $122.1(35.1)$ \\
\hline$A_{U}, h \cdot n g / m L$ & $2,054.3(500.1)$ & $2,506.3(630.2)$ & $3,820.6(863.4)$ & $5,240.1(1,343.2)$ \\
\hline $\mathrm{AUC}_{0-\infty}, \mathrm{h} \cdot \mathrm{ng} / \mathrm{mL}$ & $2,101.0(516.9)$ & $2,587.8(649.9)$ & $4,016.4(995.4)$ & $5,900.8(I, 799.3)$ \\
\hline$T_{\max }$, hours $^{\mathrm{a}}$ & $5.5(4,8)$ & $7.0(6,12)$ & $9.0(6,12)$ & $7.0(6,24)$ \\
\hline$T_{1 / 2}^{\max }$, hours & $13.5(2.8)$ & $17.3(3.5)$ & $19.1(4.6)$ & $27.7(7.4)$ \\
\hline $\mathrm{CL} / \mathrm{F}, \mathrm{L} / \mathrm{h}$ & $20.5(7.1)$ & I $6.7(5.9)$ & $10.5(2.5)$ & $7.3(1.9)$ \\
\hline $\mathrm{CL}_{r}, \mathrm{~mL} / \mathrm{min}$ & $175.9(42.7)$ & I 14.7 (24.3) & $69.9(17.9)$ & $28.6(I I .6)$ \\
\hline$V_{s s} / F, L$ & $462.3(121.8)$ & $492.7(203.7)$ & $355.3(72.5)$ & $315.3(81.4)$ \\
\hline$V^{\text {ss }} / \mathrm{F}, \mathrm{L}$ & $387.2(107.0)$ & 422.0 (202.9) & $280.3(59.3)$ & $283.1(77.7)$ \\
\hline $\mathrm{Ae}_{0-t}, \mathrm{mg}$ & $20.8(3.7)$ & $16.9(4.6)$ & $15.7(4.3)$ & $8.7(3.6)$ \\
\hline Fraction of dose, $\%$ & $51.9(9.3)$ & $42.3(\mathrm{II} .6)$ & $39.2(10.7)$ & $21.9(9.0)$ \\
\hline \multicolumn{5}{|c|}{ N-desethyl levomilnacipran } \\
\hline$C_{\max }, \mathrm{ng} / \mathrm{mL}$ & $7.1(3.0)$ & $9.3(3.6)$ & $12.6(6.9)$ & $27.8(19.9)$ \\
\hline $\mathrm{AUC}_{0-t}, \mathrm{~h} \cdot \mathrm{ng} / \mathrm{mL}$ & $201.9(109.0)$ & $325.5(137.8)$ & $668.5(339.5)$ & $\mathrm{I}, 892.4(1,380.5)$ \\
\hline $\mathrm{AUC}_{0-\infty}, \mathrm{h} \cdot \mathrm{ng} / \mathrm{mL}$ & $264.6(85.7)$ & $387.5(114.5)$ & $740.2(375.3)$ & $3,110.3(2,156.1)$ \\
\hline$T_{\max }$, hours $^{\mathrm{a}}$ & $10.0(10,12)$ & $12.0(10,36)$ & $30.0(12,26)$ & $36.0(24,48)$ \\
\hline$T_{1 / 2}^{\max }$, hours & $16.1(2.2)$ & $25.2(18.5)$ & $22.1(5.3)$ & $45.8(9.5)$ \\
\hline $\mathrm{CL}_{\mathrm{r}}, \mathrm{mL} / \mathrm{min}$ & 366.7 (I53.4) & $213.0(51.4)$ & $122.6(27.0)$ & $45.1(24.1)$ \\
\hline $\mathrm{Ae}_{0-t^{\prime}}^{\mathrm{r}}, \mathrm{mg}$ & $3.7(1.9)$ & $4.2(1.8)$ & $4.6(2.0)$ & $5.1(3.1)$ \\
\hline
\end{tabular}

Note: a Median value (minimum, maximum).

Abbreviations: $\mathrm{Ae}_{0--}$, cumulative amount of compound excreted into urine from time zero to time $t$; $A \cup C_{0-\infty}$, area under the plasma concentration versus time curve from time zero to infinity; $A \cup C_{0-t}$, area under the plasma concentration time curve from time zero to time $t$; $C_{\max }$, maximum plasma drug concentration; $\mathrm{CL} / \mathrm{F}$, total clearance of the drug from plasma after extravascular administration; $\mathrm{CL}_{r}$, renal clearance; Fraction of dose, percentage of compound excreted unchanged in urine relative to administered dose; ER, extended release; SD, standard deviation; $T_{1 / 2}$, terminal elimination half-life; $T_{\max }$, time of maximum plasma drug concentration; $V_{\mathrm{ss}} / \mathrm{F}$, apparent volume of distribution at steady state after extravascular administration; $V_{z} / F$, apparent volume of distribution during the terminal phase after extravascular administration. 
A

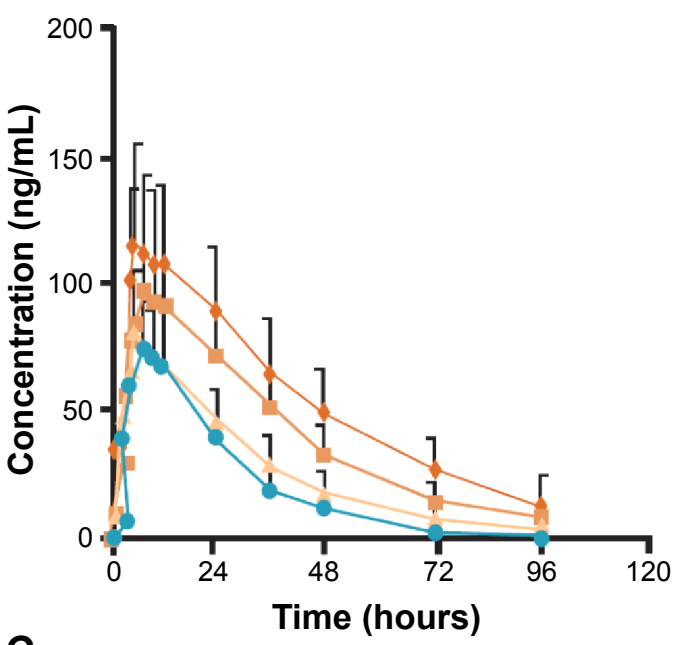

C

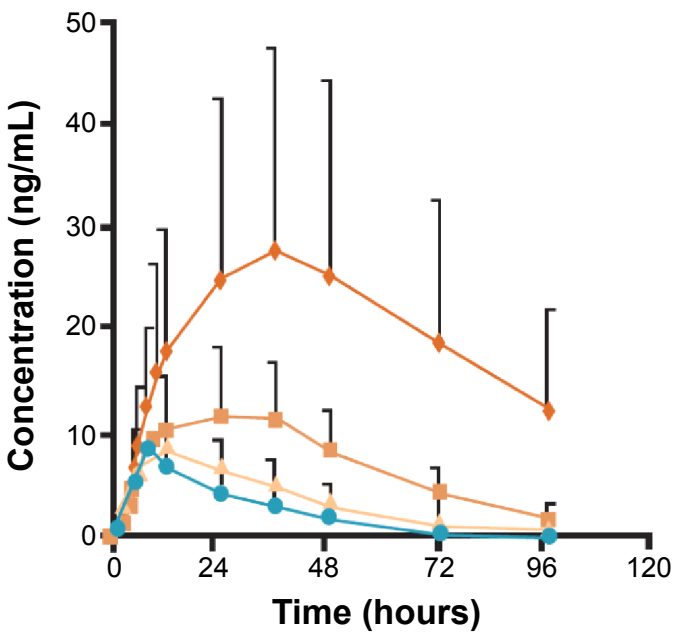

B

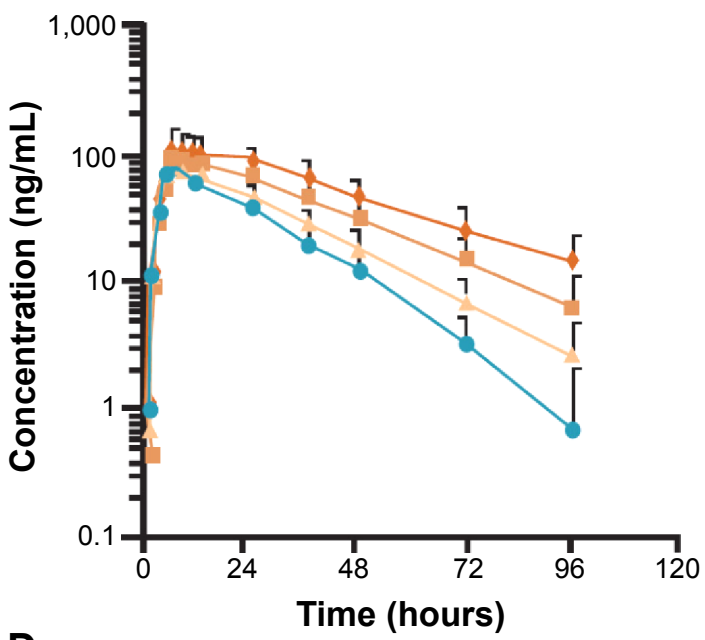

D

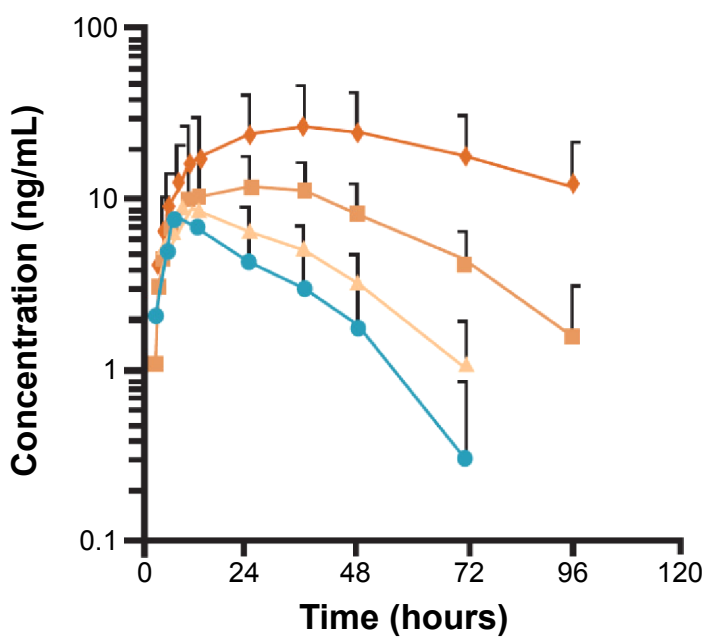

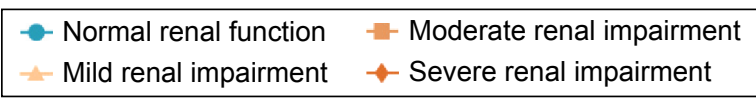

Figure I Mean (SD) plasma concentration versus time following a single dose of $40 \mathrm{mg}$ levomilnacipran ER by renal function.

Notes: (A) Mean plasma concentration versus time curves for levomilnacipran (linear scale); (B) mean plasma concentration versus time curves for levomilnacipran (semi-log scale); (C) mean plasma concentration versus time curves for $\mathrm{N}$-desethyl levomilnacipran (linear scale); (D) mean plasma concentration versus time curves for $\mathrm{N}$-desethyl levomilnacipran (semi-log scale).

Abbreviations: ER, extended release; SD, standard deviation.

impairment, levomilnacipran $C_{\max }$ was $4 \%$ lower, and $19 \%$ and $44 \%$ higher, respectively, and $\mathrm{AUC}_{0-\infty}$ was $23 \%, 93 \%$, and $180 \%$ higher, respectively, relative to participants with normal renal function (Table 3). In participants with mild, moderate, and severe renal impairment, $N$-desethyl levomilnacipran $C_{\max }$ was $34 \%, 77 \%$, and $236 \%$ higher, respectively, and $\mathrm{AUC}_{0-t}$ was $101 \%, 309 \%$, and $898 \%$ higher, respectively, compared with the respective values obtained in participants with normal renal function (Table 3 ). In addition, the $90 \%$ confidence intervals of the geometric mean ratios were outside the upper boundary of $80 \%-125 \%$. AUC $_{0-\infty}$ of $N$-desethyl levomilnacipran was not compared between normal and renal impairment groups because the
$\mathrm{AUC}_{0-\infty}$ in participants with severe renal impairment could not be determined reliably.

The $T_{1 / 2}$ of levomilnacipran was prolonged as severity of renal impairment increased, averaging 27.7 hours in participants with severe renal impairment compared with 13.5 hours in participants with normal renal function (Table 2). Prolongation of the $T_{1 / 2}$ was also found for $N$-desethyl levomilnacipran in participants with renal impairment, averaging 45.8 hours in participants with severe renal impairment compared with 16.1 hours in participants with normal renal function.

Mean CL/F and $\mathrm{CL}_{\mathrm{r}}$ of levomilnacipran decreased with increased renal impairment (Table 2). Mean $V_{\mathrm{ss}} / \mathrm{F}$ and $V_{\mathrm{z}} / \mathrm{F}$ 
Table 3 Pharmacokinetic parameters expressed as geometric mean ratios $(90 \% \mathrm{Cl})$ following a single dose of $40 \mathrm{mg}$ levomilnacipran ER

\begin{tabular}{|c|c|c|c|}
\hline Pharmacokinetic parameters & Mild/normal & Moderate/normal & Severe/normal \\
\hline \multicolumn{4}{|l|}{ Levomilnacipran } \\
\hline$C_{\max }, \mathrm{ng} / \mathrm{mL}$ & $96.1(75.5-122.4)$ & $119.3(93.7-151.8)$ & | 43.5 (| | 2.8-182.7) \\
\hline$A \cup C_{0-t}, h \cdot n g / m L$ & $121.8(96.9-153.1)$ & $187.9(149.5-236.2)$ & $256.1(203.8-321.9)$ \\
\hline $\mathrm{AUC}_{0-\infty}, \mathrm{h} \cdot \mathrm{ng} / \mathrm{mL}$ & I23.I (96.9-I56.3) & $192.5(151.6-244.5)$ & $279.7(220.2-355.2)$ \\
\hline \multicolumn{4}{|l|}{ N-desethyl levomilnacipran } \\
\hline$C_{\max }, \mathrm{ng} / \mathrm{mL}$ & I 33.8 (72.2-247.8) & $177.2(95.6-328.2)$ & $336.2(181.5-622.8)$ \\
\hline $\mathrm{AUC}_{0-t}, \mathrm{~h} \cdot \mathrm{ng} / \mathrm{mL}$ & $201.3(94.4-429.2)$ & $408.5(191.6-871.0)$ & $997.8(468.0-2,127.3)$ \\
\hline
\end{tabular}

Abbreviations: $\mathrm{AUC}_{0-\infty}$, area under the plasma concentration versus time curve for time zero to infinity; $\mathrm{AUC}_{0-t}$, area under the plasma concentration time curve for time zero to time $t ; C_{\max }$, maximum plasma drug concentration; $\mathrm{Cl}$, confidence interval; $\mathrm{ER}$, extended release.

were lower in the severe and moderate renal impairment groups than in the other groups (Table 2). Linear correlations were found between $\mathrm{CL} / \mathrm{F}$ and $\mathrm{CL}_{\mathrm{cr}}(R=0.8043)$ and between $\mathrm{CL}_{\mathrm{r}}$ and $\mathrm{CL}_{\mathrm{cr}}(R=0.9152)$ (Table 4; Figure 2).

$\mathrm{CL} / \mathrm{F}$ values derived from the linear regression analysis were $16.7 \mathrm{~L} / \mathrm{h}, 11.7 \mathrm{~L} / \mathrm{h}$, and $8.0 \mathrm{~L} / \mathrm{h}$ for an individual with mild, moderate, or severe renal impairment, respectively (Table 5). On the basis of the change in predicted $\mathrm{CL} / \mathrm{F}$ for each renally impaired group compared with the normal renal function group, levomilnacipran ER doses of $120 \mathrm{mg}, 80 \mathrm{mg}$, and $40 \mathrm{mg}$ were recommended for the mild, moderate, and severe renal impairment groups, respectively.

\section{Safety and tolerability}

No deaths, serious AEs, or discontinuations as a result of AEs or otherwise occurred during the study. Overall, $40.6 \%$ (13/32) of all participants experienced at least one TEAE. TEAEs that occurred in $\geq 5 \%$ of all study participants were as follows: nausea (15.6\%), vomiting $(15.6 \%)$, headache $(12.5 \%)$, and diarrhea (9.4\%). TEAEs did not occur more frequently in participants with moderate or severe renal impairment than in participants with normal renal function.

Increases in mean heart rate were observed in all groups (range, $7.0 \mathrm{bpm}$ in participants with normal renal function to $10.9 \mathrm{bpm}$ in participants with moderate renal impairment). Increases in mean systolic $(3.0 \mathrm{mmHg})$ and diastolic blood pressure $(4.1 \mathrm{mmHg})$ occurred in the group with moderate renal impairment. During the pharmacokinetic profiling

Table 4 Slope (b) and intercept (a) estimates ( \pm standard error) for regression analyses

\begin{tabular}{llll}
\hline Relationship & $\mathbf{a}$ & $\mathbf{b}$ & $\boldsymbol{R}$ \\
\hline $\mathrm{CL} / \mathrm{F}-\mathrm{CL}_{\mathrm{cr}}$ & $4.32 \pm 1.48$ & $0.17 \pm 0.02$ & 0.80 \\
$\mathrm{CL}-\mathrm{CL}_{\mathrm{cr}}$ & $3.62 \pm 8.73$ & $1.64 \pm 0.13$ & 0.92 \\
\hline
\end{tabular}

Note: Linear polynomial equation: $Y=a+b \cdot X$.

Abbreviations: $\mathrm{CL} / \mathrm{F}$, total clearance of the drug from plasma after extravascular administration; $\mathrm{CL}_{c r}$, creatinine clearance; $\mathrm{CL}_{\mathrm{r}}$, renal clearance; $R$, correlation coefficient. period (time between dosing and end of study), one participant with mild renal impairment had a potentially clinically significant high diastolic blood pressure (ie, $\geq 105 \mathrm{mmHg}$ and $\geq 15 \mathrm{mmHg}$ increase from the value at screening) on day 1 at 12 hours postdose. At the end of study, no participant had any potentially clinically significant changes in blood pressure or heart rate.

Except for increases in mean heart rate that were comparable among all groups, there were no notable changes in ECG measurements. No notable changes in mean laboratory values were detected during the study in any groups. No participant exhibited suicidal ideation or behavior before or during the study.

\section{Discussion}

The major finding of this study was that exposure to levomilnacipran is increased as a function of the severity of renal impairment. Previous studies have established that levomilnacipran has linear pharmacokinetics and that steady-state exposure is predictable from single-dose data. ${ }^{1}$ Therefore, the dose adjustment recommendations given in this article (ie, based on this single-dose study) are applicable to patients receiving a multiple-dose regimen of levomilnacipran ER at all therapeutic doses ranging from $40 \mathrm{mg}$ /day to $120 \mathrm{mg}$ /day.

About $50 \%$ of the administered levomilnacipran dose was recovered unchanged in the urine from participants with normal renal function in this study (Table 2), which is in agreement with observations from other studies, ${ }^{1}$ indicating that urinary excretion of levomilnacipran is the primary elimination pathway. Comparing the $\mathrm{CL}_{\mathrm{r}}$ of levomilnacipran $(175.9 \mathrm{~mL} / \mathrm{min})$ to the total clearance $(\mathrm{CL} / \mathrm{F})$ of levomilnacipran $(341.7 \mathrm{~mL} / \mathrm{min})$ in participants with normal renal function indicates that $51 \%$ elimination of levomilnacipran is due to renal excretion (Table 2).

Only a modest increase (1.2-fold) in the $\mathrm{AUC}_{0-\infty}$ value was observed for patients with mild renal impairment compared with individuals with normal renal function. 
A

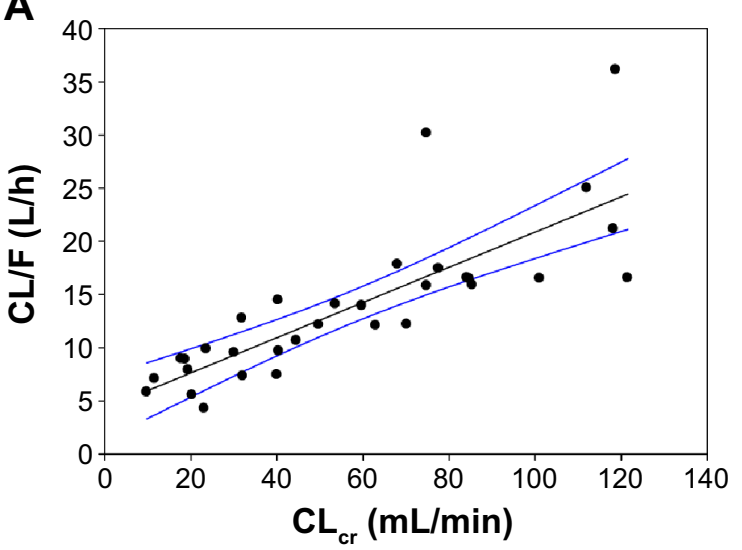

B

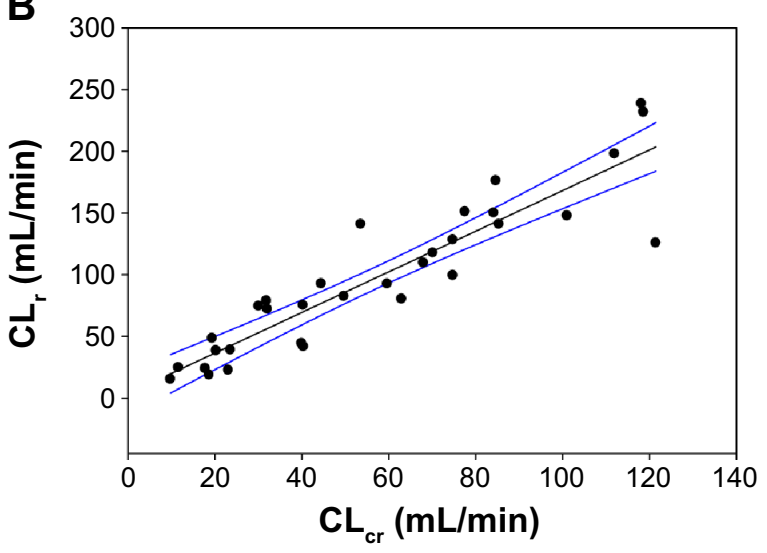

Figure 2 Apparent total clearance $(\mathrm{CL} / \mathrm{F})$ and renal clearance $\left(\mathrm{CL}_{\mathrm{r}}\right)$ of levomilnacipran: relationships to creatinine clearance $\left(\mathrm{CL}_{\mathrm{cr}}\right)$. Notes: (A) Total clearance; (B) renal clearance. Black line, linear regression; blue lines on either side of the black line, $95 \%$ confidence bands.

Thus, no dose adjustment is recommended in patients with mild renal impairment. The pharmacokinetic analysis showed that moderate and severe renal impairment resulted in an approximately 2-fold and 3-fold increase in levomilnacipran $\mathrm{AUC}_{0-\infty}$, respectively. Levomilnacipran shows greater exposure and longer $T_{1 / 2}$ in patients with moderate and severe renal impairment; therefore, dosing modifications of levomilnacipran ER are warranted in these patients. Based on the observed relationship between $\mathrm{CL} / \mathrm{F}$ and $\mathrm{CL}_{\mathrm{cr}}$ and considering the overall safety profile of levomilnacipran ER in clinical trials ${ }^{6-10}$ and the available capsule strengths of $20 \mathrm{mg}, 40 \mathrm{mg}, 80 \mathrm{mg}$, and $120 \mathrm{mg}$, a maximum dose of $80 \mathrm{mg} /$ day and $40 \mathrm{mg} /$ day is recommended for moderate and severe renal impairment, respectively (Table 5). This dose adjustment will result in exposures similar to those seen in individuals with normal renal function.

The increases in $C_{\max }$ and AUC values of $N$-desethyl levomilnacipran, the inactive metabolite of levomilnacipran, as a result of renal impairment were greater than those observed for levomilnacipran. Up to a 9-fold increase in $\mathrm{AUC}_{0-t}$ of $N$-desethyl levomilnacipran was observed in patients with severe renal impairment compared with individuals with normal renal function. Because $\mathrm{CL}_{\mathrm{r}}$ of $\mathrm{N}$-desethyl levomilnacipran is approximately twice that of levomilnacipran, renal function may play a more important role in removing $N$-desethyl levomilnacipran from the body than it does for levomilnacipran. This metabolite is pharmacologically inactive and its formation in the body is relatively low ( $\sim 18 \%$ of the levomilnacipran dose administered). ${ }^{1}$ Furthermore, based on preclinical toxicology studies, the plasma concentrations of this metabolite following doses that were found to be safe in rat and monkey were higher than those observed at the recommended therapeutic doses in humans (data on file at Forest).

One demographic difference was noted among the renal groups evaluated in this study. The moderate renal impairment group had a lower percentage of women than the other groups $(37.5 \%$ versus $>60 \%$ for the other groups). This imbalance of female study participants among the study groups is not expected to have any impact on levomilnacipran ER dosing recommendations for renal impairment because there are no differences in levomilnacipran pharmacokinetics between males and females. ${ }^{1}$

Results of a separate, multiple-dose study (data on file at Forest), which compared the pharmacokinetics of levomilnacipran in elderly adults ( $>65$ years old) with those of younger adults (18-45 years old) indicated that age does not have a significant impact on the AUC and $C_{\max }$ of levomilnacipran ER. Therefore, dose adjustments are not recommended in the elderly, unless renal function is impaired.

Table 5 Recommendation of maximum levomilnacipran ER doses in renal impairment

\begin{tabular}{lllll}
\hline Renal function group & $\mathbf{C L}_{\mathbf{c r}}(\mathbf{m L} / \mathbf{m i n})$ & CL/F $(\mathbf{L} / \mathbf{h})$ & Calculated dose $(\mathbf{m g})$ & Recommended dose $(\mathbf{m g})$ \\
\hline Normal & 105 & 21.7 & 120 & 120 \\
Mild impairment & $74.5^{\mathrm{a}}$ & 16.7 & 92 & 120 \\
Moderate impairment & $44.5^{\mathrm{a}}$ & 11.7 & 65 & 80 \\
Severe impairment & $22^{\mathrm{a}}$ & 8.0 & 44 & 40 \\
\hline
\end{tabular}

Notes: aMidpoint values of renal impaired groups were determined on the basis of the draft guidance of US Food and Drug Administration (20I0). ${ }^{5}$ For the normal renal function group, the range of $\mathrm{CL}_{\mathrm{cr}}$ was assumed to be $90-120 \mathrm{~mL} / \mathrm{min}$.

Abbreviations: $\mathrm{CL} / \mathrm{F}$, total clearance of the drug from plasma after extravascular administration; $\mathrm{CL}_{c r}$, $\mathrm{creatinine}^{\mathrm{clearance}} \mathrm{ER}$, extended release. 
Levomilnacipran ER was generally well tolerated by study participants with normal renal function as well as by patients with mild, moderate, and severe renal impairment. AEs were consistent with the known safety profile derived from both the large Phase I program and the Phase II/III placebo-controlled studies. ${ }^{6-10}$ The presence and severity of renal impairment had no apparent impact on the incidence of AEs.

In summary, the results of this single-dose, open-label parallel-group study in patients with renal impairment show that renal impairment significantly increased exposure to levomilnacipran. Although no dose adjustment of levomilnacipran is needed for patients with mild renal impairment, dosing adjustments are recommended in patients with moderate or severe renal impairment. The recommended maximum maintenance dose of levomilnacipran ER is $80 \mathrm{mg}$ once daily for patients with moderate renal impairment and $40 \mathrm{mg}$ once daily for patients with severe renal impairment.

\section{Acknowledgments}

Medical writing and editorial support were provided by Dana L Randall, PharmD, and Joann Hettasch, PhD, of Arbor Communications, Inc., Ann Arbor, MI, USA, and funded by Forest Research Institute, Inc., a subsidiary of Actavis, Inc., Jersey City, NJ, USA.

\section{Funding source}

The study was supported by funding from Forest Research Institute, a subsidiary of Actavis, Inc., Jersey City, NJ, USA, and Pierre Fabre Médicament, Boulogne, France. Forest Laboratories was involved in the study design, data collection, data analysis and interpretation, and the decision to publish these results.

\section{Author contributions}

All authors contributed toward data analysis, drafting and critically revising the paper and agree to be accountable for all aspects of the work.

\section{Disclosure}

L Chen, A Periclou, and P Ghahramani are employees of Forest Research Institute and may own company shares. WM Greenberg, E Brand-Schieber, and J Wangsa were employees of Forest Research Institute at the time this research was conducted. The authors report no other conflicts of interest in this work.

\section{References}

1. Forest Pharmaceuticals, Inc. FETZIMA ${ }^{\mathrm{TM}}$ (levomilnacipran) extendedrelease capsules [package insert]. St Louis, MO: Forest Pharmaceuticals, Inc.; 2014.

2. Cockcroft DW, Gault MH. Prediction of creatinine clearance from serum creatinine. Nephron. 1976;16:31-41.

3. US Food and Drug Administration. Guidance for industry: pharmacokinetics in patients with impaired renal function - study design, data analysis, and impact on dosing and labeling; 1998. Available from: http://www.fda.gov/downloads/Drugs/GuidanceComplianceRegulatory Information/Guidances/UCM072127.pdf. Accessed August 22, 2013.

4. Chen L, Boinpally R, Greenberg WM, Wangsa J, Periclou A, Ghahramani P. Effect of hepatic impairment on the pharmacokinetics of levomilnacipran following a single oral dose of a levomilnacipran extended-release capsule in human participants. Clin Drug Investig. 2014;34:351-359.

5. US Food and Drug Administration. Guidance for industry: pharmacokinetics in patients with impaired renal function - study design, data analysis, and impact on dosing and labeling. Draft guidance; 2010. Available from: http://www.fda.gov/downloads/Drugs/Guidances/ UCM204959.pdf. Accessed August 22, 2013.

6. Asnis G, Bose A, Gommoll C, Chen C, Greenberg WM. The efficacy and safety of levomilnacipran SR $40 \mathrm{mg}, 80 \mathrm{mg}$, or $120 \mathrm{mg}$ in major depressive disorder: a phase III, randomized, double-blind, placebocontrolled study. J Clin Psychiatry. 2013;74:242-248.

7. Bakish D, Bose A, Gommoll C, et al. Levomilnacipran ER $40 \mathrm{mg}$ and $80 \mathrm{mg}$ in patients with major depressive disorder: a phase III, randomized, double-blind, fixed-dose, placebo-controlled study. J Psychiatry Neurosci. 2014;39:40-49.

8. Montgomery S, Mansuy L, Ruth A, Bose A, Li H, Li D. The efficacy and safety of levomilnacipran SR in major depressive disorder: a randomized, double-blind, placebo-controlled, proof-of-concept study. J Clin Psychiatry. 2013;74:363-369.

9. Sambunaris A, Bose A, Gommoll CP, Chen C, Greenberg WM, Sheehan DV. A phase III, double-blind, placebo-controlled, flexibledose study of levomilnacipran extended-release in patients with major depressive disorder. J Clin Psychopharmacol. 2014;34:47-56.

10. Gommoll CP, Greenberg WM, Chen C. A randomized, double-blind, placebo-controlled study of flexible doses of levomilnacipran ER (40-120 mg/day) in patients with major depressive disorder. J Drug Assess. 2014;3:10-19.
Drug Design, Development and Therapy

\section{Publish your work in this journal}

Drug Design, Development and Therapy is an international, peerreviewed open-access journal that spans the spectrum of drug design and development through to clinical applications. Clinical outcomes, patient safety, and programs for the development and effective, safe, and sustained use of medicines are a feature of the journal, which

\section{Dovepress}

has also been accepted for indexing on PubMed Central. The manuscript management system is completely online and includes a very quick and fair peer-review system, which is all easy to use. Visit $\mathrm{http}: / /$ www.dovepress.com/testimonials.php to read real quotes from published authors. 